\title{
THE NATIONAL COLLECTION OF TYPE CULTURES.
}

\author{
By R. St John Brooks, M.D., D.P.H., M.A.
}

The inception of the National Collection of Type Cultures was due to the initiative of the Medical Research Committee (now the Medical Research Council), who had long had in view the formation of a collection. where biologists in general and bacteriologists in particular might obtain authentic strains of bacteria, protozoa, etc., for use in scientific work. The need of an available supply of this kind had long been felt in many directions and particularly in medical research work, for the study of principles and methods in bacteriological technique and for the systematic classification of bacteria, protozoa, etc., in their various species and strains.

In the past the needs of workers in this respect had never been fully met. In this country the Lister Institute of Preventive Medicine had for many years assisted bacteriologists both at home and abroad, so far as the resources of its own private collection permitted, but British workers had been dependent in great part upon the courtesy of scientific colleagues or upon the collections of Institutes in other countries. Before the war the collection of the Pasteur Institute in Paris, maintained by M. Binot, was very helpful to workers here. A collection of type cultures was formerly maintained on a commerical basis by Král at Prague and this was subsequently transferred to the Sero-physiological Institute of Vienna. In America, the Museum of Natural History in New York has maintained a Culture Bureau during the last nine years and it is believed that the activities of the Bureau have been of the greatest benefit to workers there.

Early last year the Medical Research Council were able, by the courtesy of the Governing Body of the Lister Institute, to make arrangements to maintain a National Collection of Type Cultures at the Institute, where all the necessary facilities had been provided. The scheme is under the general direction, on behalf of the Council, of Prof. J. C. G. Ledingham, a member of the Staff of the Lister Institute, the writer being appointed by the Council to be Curator of the Collection with Miss M. Rhodes as Assistant Curator.

Since the formation of the Collection in January I92I some twelve hundred strains of micro-organisms of medical, veterinary and economic importance have been incorporated in the collection and cultures have been distributed to workers at home and 
abroad at the rate of about two thousand per annum. This number is expected to show considerable increase in the not distant future. A catalogue giving all the strains conserved up to date is at present in the press and is expected to be available for distribution very shortly. The Staff are prepared to give assistance in the identification and classification of strains sent in by correspondents.

\section{Mycological Collection.}

During the early part of the current year it was proposed to extend the scope of the National Collection by including representative fungi derived from various sources. As was the case with bacteria, so also the need of a Mycological Collection had long been felt. To some extent the Centraalbureau voor Schimmelcultures, Amsterdam (now at Baarn), had been found useful by British and Imperial botanists, but it was the general opinion that a collection of fungi in this country was very necessary for the co-ordination of research. No other Institution contemplated the formation of such a collection at that time and the National Collection was glad to be in a position to offer its services to Mycologists. In order to insure that this side of the collection might be made of the most value, the British Mycological Society were asked to appoint a fully representative standing committee to advise and assist in all questions appertaining to fungi. The following members of the Society were appointed:
Prof. V. H. Blackman
Mr W. B. Brierley
Mr F. T. Brooks
Dr E. J. Butler (Chairman)
Mr A. D. Cotton
Mr J. Ramsbottom
Dr R. St John Brooks
Miss E. M. Wakefield.

The scope of the Mycological Collection includes the collection and maintenance of cultures of fungi of importance in phytopathology, medicine, veterinary science, technology and soil biology, types useful for teaching purposes and any rare or interesting species. At present it is not possible to cope with the innumerable strains of common fungi and only room can be found for those forms with some published distinguishing name or symbol.

It is found necessary at present to restrict the collection to fully identified species of fungi and in sending these it should be stated by whom they were named, and also whether a special medium is required for their growth, as only a few standard media are in general use in the collection. It must naturally be left to the discretion of the Curator and the Advisory Committee to decide whether given cultures are of 
National Collection of Type Cultures. R. St John Brooks. 239

sufficient importance to be maintained in the collection. Cultures will be supplied on demand, so far as possible, to workers at home and abroad and, as a rule, a small charge will be made to defray the cost of media and postage.

Annual lists of the fungi in the collection will be published in the Transactions of the British Mycological Society. A set of type slides of fungi will be kept in the Botanical Department of the British Museum (Natural History) in addition to a working set at the Lister Institute.

\title{
NOTES ON MALAYAN MYCETOZOA.
}

\author{
By A. R. Sanderson, F.L.S.
}

The part of the Malayan Peninsula dealt with in the present paper lies between North Latitude $I^{\circ}$ and $6^{\circ}$ and East Longitude ${ }^{100^{\circ}}$ and $104^{\circ}$. It is a long narrow spit of land pointing south. An irregular ridge of mountains extends from north to south of the peninsula, some of the peaks rise to over $6000 \mathrm{ft}$., but all are clothed to the summit with tropical forest.

The climate throughout the year is warm, moist and equable; the rainfall is abundant and not confined to any one season (see notes on rainfall below), the tropical vegetation is luxuriant.

Apart from gatherings by Haviland, Burkill, Chipp and Sappan, very few records for Mycetozoa in Malaya existed prior to I9I8. Although a considerable number have been added since, the present paper cannot claim to be more than a preliminary report, the observations as noted being records made at odd moments and at more or less irregular intervals; they merely indicate what a fruitful field awaits the enthusiast who has ample time at his disposal to investigate the distribution in the tropics not only of Mycetozoa but of fungi and cryptogams in general.

Before proceeding to deal with the various species of Malayan Mycetozoa and their habitats, it is advisable to consider the peculiar conditions prevailing in Malaya, more particularly along the western half, that is over all of the peninsula bounded on the east by the natural barrier of mountains.

Large tracts of tropical virgin forest have been cut down, one might almost say ruthlessly destroyed, in order to clear land chiefly for the purpose of planting rubber trees, Hevea brasiliensis. It is likely that further portions of forest will share the same fate in the near future, especially in the states of Pahang. and Kelantan which lie in the eastern half of the peninsula. Probably over one and a half million acres of the land which 